\title{
Hereditary Ataxia, Spastic Paraparesis and Neuropathy in the French-Canadian Population
}

\author{
Nicolas Dupré, Jean-Pierre Bouchard, Bernard Brais, Guy A. Rouleau
}

\begin{abstract}
Historical events have shaped the various regional gene pools of the French-Canadian (FC) population, leading to increased prevalence of some rare diseases. The first studies of these founder effects were performed in large part by astute clinicians such as André Barbeau. In collaboration with others, he contributed greatly to the delineation of phenotypic subtypes of these conditions. As such, the following neurogenetic disorders were first identified in patients of FC origin: AOA2, ARSACS, HSAN2, RAB, and HMSN/ACC. We have summarized our current knowledge of the main hereditary ataxias, spastic parapareses and neuropathies that are particular to the FC population. The initial genetic characterization of the more common and homogeneous of these diseases has been largely completed. We predict that the regional populations of Canada will allow the identification of new rare forms of hereditary ataxias, spastic parapareses and neuropathies, and contribute to the unravelling of the genetic basis of these entities.
\end{abstract}

RÉSUMÉ: Ataxie héréditaire, paraparésie spastique et neuropathie dans la population canadienne-française. Des événements historiques ont façonné les différents pools géniques de la population canadienne-française (CF) entraînant une augmentation de la prévalence de certaines maladies rares. Les premières études de ces effets fondateurs ont été effectuées surtout grâce à des cliniciens perspicaces tel André Barbeau. Avec des collaborateurs, il a contribué de façon importante à la description de sous-types phénotypiques de ces maladies. Parmi ces maladies neurogénétiques, citons 1'AOA2, l'ARSACS, l'HSAN2, le RAB et 1'HMSN/ACC qui ont été décrites pour la première fois chez des patients canadiens-français. Nous résumons les connaissances actuelles sur les principales ataxies héréditaires, les paraparésies spastiques et les neuropathies qui sont particulières à la population canadiennefrançaise. La caractérisation génétique des maladies qui sont plus fréquentes et plus homogènes est en grande partie complétée. Nous prévoyons que les populations régionales du Canada permettront d'identifier de nouvelles formes rares d'ataxies héréditaires, de paraparésies spastiques et de neuropathies et contribueront à élucider le fondement génétique de ces maladies.

Can. J. Neurol. Sci. 2006; 33: 149-157

The Provinces of Quebec and New Brunswick were amongst the earliest territories in North America to be colonized by Europeans. As early as 1600 , the trading post of Tadoussac was established at the point where the Saguenay and the St-Lawrence rivers meet. In 1608, Quebec City was founded under the rule of the French Monarchy by Samuel de Champlain. The peak of the colonial expansion under French rule was the second half of the $17^{\text {th }}$ century. The majority of French Canadians (FC) living in the Province of Quebec today descend from these initial founders. ${ }^{1}$ The Maritime Provinces of New Brunswick and Nova Scotia, formerly called Acadia, were much disputed between the French and British Empires throughout the $17^{\text {th }}$ and $18^{\text {th }}$ centuries, which brought different waves of settlers. ${ }^{2}$ The first settlements in Acadia were founded by the French in the early $17^{\text {th }}$ century. The most dramatic event in the history of the Acadians was their large scale deportation by the British Crown

From the Department of Neurological Sciences (ND, JPB), CHAUQ-Enfant-Jésus, Quebec City, QC; Center for the Study of Brain Diseases, CHUM Research Center (BB, GAR), Notre Dame Hospital, Montreal, QC, Canada.

Received June 30, 2005. AcCePted In FINAL Form November 18, 2005. Reprint requests to: Nicolas Dupré, Faculty of Medicine, Laval University, Department of Neurological Sciences, CHAUQ-Enfant-Jésus, 1401, 18th Street, Quebec City, Quebec, G1J 1Z4, Canada. 
initiated in 1755. Some were transported as far as Louisiana, where they became known as "Cajun". Many fled to various parts of Nouvelle-France, settling in various cities and in neighbouring regions such as the Gaspésie peninsula. Therefore, a large proportion of FCs living in Quebec today have some Acadian ancestry. Under British rule since 1755, the Provinces of New Brunswick and Nova Scotia were later created. ${ }^{2}$ A sizeable number of Acadians today still live in these provinces, mainly concentrated in the northern part of New Brunswick.

One of the main historical contributors to the study of inherited neurological disorders in the FC population is André Barbeau (1931-1986) (Figure). He lead multiple initiatives that resulted in the description of different forms of hereditary ataxias, neuropathies, and spastic parapareses. ${ }^{3}$ From 1974 to 1986, on behalf of the Quebec Collaborative Study on Friedreich's Ataxia, he edited six supplements of the Canadian Journals of Neurological Sciences. Later, his work was carried through the genomic era, with the description of different distinct phenotypic and genotypic entities. In the current article, we provide an overview of the main hereditary ataxias, spastic parapareses and neuropathies that have been described to date in the FC population (Table), most of which stems directly from the work of André Barbeau. We are currently working on the identification and characterization of an even wider spectrum of these disorders in this population with many founder effects.

\section{The Hereditary Ataxias}

\section{Friedreich Ataxia 1}

(FRDA; MIM 229300)

\section{Clinical features}

Progressive, unremitting ataxia is the principal feature Friedreich Ataxia (FRDA), which usually begins around puberty with clumsiness in gait. Age of onset may vary from two years to well over 25 years. According to Harding, ${ }^{4}$ the essential features are (1) autosomal recessive inheritance, (2) onset before 25 years of age, (3) progressive limb and gait ataxia, (4) absent tendon reflexes in the lower extremities, (5) electrophysiologic evidence of axonal sensory neuropathy followed by (within five years of onset): dysarthria, areflexia at all four limbs, loss of distal position and vibration sense, extensor plantar response, and pyramidal weakness of the legs. Other clinical features include cardiomyopathy, scoliosis, diabetes, and hearing loss. Nerve conduction studies demonstrate an axonal sensory neuropathy, with small or absent sensory action potentials. ${ }^{5}$ Compound muscle action potentials (C-MAPs) are either normal or show slight reduction in amplitudes and velocities. Magnetic resonance imaging (MRI) reveals atrophy of the spinal cord, with normal brainstem and cerebellum. ${ }^{5}$

\section{Epidemiology, Genetics, and Pathophysiology}

Friedreich Ataxia is the most common hereditary ataxia worldwide, with an estimated prevalence in Caucasians of 1/29000-1/50000. ${ }^{5}$ As part of the Quebec Cooperative Study of Friedreich's Ataxia, Jean-Pierre Bouchard and André Barbeau initially described a cluster of eight closely related kindreds with typical FRDA in the Rimouski area of Quebec. ${ }^{6}$ Subsequently, they studied the complete genealogy of 14 kindreds scattered across Quebec, including the eight from the Rimouski area. ${ }^{7}$

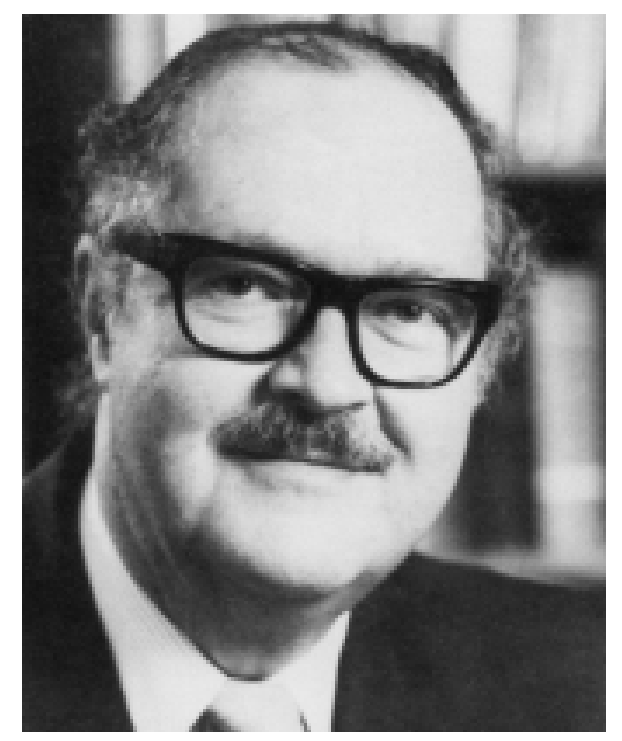

Figure: André Barbeau (1931 - 1986).

They suggested that the ancestral couple which presumably introduced a FRDA mutation in Quebec arrived in NouvelleFrance in 1634 from Perche (northwest of France). ${ }^{7}$ That couple was given a land concession in Beauport, near Quebec City, and was thus not of Acadian ancestry. Subsequently, a founder effect could not be demonstrated using haplotypes in FC patients from Quebec, suggesting that more than one mutation was introduced in this population. ${ }^{8}$ This is not entirely surprising, considering the predicted carrier rate for FRDA mutations in Europeans of $1 / 60-1 / 100$ and the estimated more than 10,000 French founders who arrived during the French Regime.

Friedreich Ataxia was also studied in Acadians from Quebec and New Brunswick, as well as "Cajuns" from Louisiana. 9 These cases were initially thought to represent a different entity than FRDA, since they differed from the classical cases mainly in speed of progression of illness and low incidence of some of the cardinal signs. A total of 14 FRDA patients from New Brunswick of Acadian ancestry were examined, as well as 28 "Cajun" patients from Louisiana. ${ }^{9}$ Friedreich Ataxia patients from Acadian or "Cajun" ancestry were not significantly different from one another, while they differed from a control Quebec cohort in duration of illness (higher percentage living older) and cardiomyopathy (less frequent). Linkage and haplotype analysis studies confirmed that the Acadian and "Cajun" variants mapped to the FRDA locus on chromosome 9. ${ }^{10,11}$ Further haplotype analysis studies confirmed the existence of a founder effect common to the Acadian and "Cajun" FRDA cases. Both Acadian and "Cajun" FRDA cases share the same major haplotype, but this major haplotype is uncommon in the overall Caucasian FRDA patient population, as well as in the FRDA patients from Quebec who are not of Acadian ancestry. ${ }^{12,13}$

The FRDA locus was mapped initially to markers on chromosome 9q13-q21.1, and screening patients for a mutation in the X25 gene led to the identification of an expanded trinucleotide repeat (GAA) within its first intron. ${ }^{14}$ The FRDA 
Table: Hereditary ataxias, spastic parapareses and neuropathies in the French-Canadian population

\begin{tabular}{|c|c|c|c|c|c|c|c|}
\hline Diseases & OMIM & Inheritance & Geographic Region & Locus & Genes & Proteins & Mutations \\
\hline FRDA & 229300 & $\mathrm{AR}$ & Rimouski \& Acadian (NB) & $9 \mathrm{q}$ & $\mathrm{X} 25$ & FRATAXIN & GAA repeat in intron 1 \\
\hline \multirow[t]{2}{*}{$\mathrm{AOA} 2$} & 606002 & $\mathrm{AR}$ & Gaspésie & $9 \mathrm{q} 34$ & STX & SENATAXIN & $5927 \mathrm{~T} \rightarrow \mathrm{G}$ (major) \\
\hline & & & & & & & $\begin{array}{c}193 \mathrm{G} \rightarrow \mathrm{A}, 4087 \mathrm{C} \rightarrow \mathrm{T}, \text { 5070ins } \mathrm{T} \\
\text { (all minor) }\end{array}$ \\
\hline \multirow[t]{2}{*}{ ARSACS } & 270550 & AR & Charlevoix \& SLSJ & $13 q 11$ & SACS & SACSIN & g.659delT (major) \\
\hline & & & & & & & g. $5254 \mathrm{C} \rightarrow \mathrm{T}$ (minor) \\
\hline \multirow[t]{2}{*}{$\mathrm{RAB}$} & n.a. & $\mathrm{AR}$ & Bas-St-Laurent \& & ? & ? & $?$ & $?$ \\
\hline & & & Chaudière-Appalache & & & & \\
\hline \multirow[t]{3}{*}{ SPG4 } & 182601 & $\mathrm{AD}$ & PQ & $2 \mathrm{p} 22-\mathrm{p} 21$ & SPASTIN & SPASTIN & G1801A (major) \\
\hline & & & & & & & 687delG, G1004A, A1367G, C1591T, \\
\hline & & & & & & & C1321T, G1425T, A1538-2G(all minor) \\
\hline ADLD & 169500 & $\mathrm{AD}$ & Charlevoix & $5 \mathrm{q} 23$ & $?$ & $?$ & $?$ \\
\hline AMN & 300100 & $\mathrm{X}$ & PQ & $\mathrm{Xq} 28$ & ALD & ABCD1 & A294V \\
\hline SPG27 & 609041 & $\mathrm{AR}$ & PQ & $10 \mathrm{q} 22-10 \mathrm{q} 24$ & $?$ & $?$ & $?$ \\
\hline \multirow[t]{2}{*}{ HMSN/ACC } & 218000 & $\mathrm{AR}$ & Charlevoix \& SLSJ & $15 \mathrm{q}$ & SLC12A6 & $\mathrm{KCC} 3$ & c.2436delG (major) \\
\hline & & & & & & & c.1584_1585delCTinsG(minor) \\
\hline \multirow[t]{2}{*}{ LHON } & 535000 & Maternal & PQ & Mitochondrial & ND1, ND4 & Mitochondrial & T14484C (major) \\
\hline & & & & & ND61 & Complex I & G11778A, G3460A (minor) \\
\hline HSAN2 & 201300 & $\mathrm{AR}$ & PQ & $12 \mathrm{p} 13$ & HSN2 & HSN2 & c.918-919insA, c.943C $\rightarrow$ T \\
\hline HMSN1A & 118220 & $\mathrm{AD}$ & PQ & $17 \mathrm{p} 11.2$ & PMP22 & PMP22 & Duplication \\
\hline HMSNX1 & 302800 & $\mathrm{X}$ & Portneuf & $\mathrm{Xq} 13$ & CONNEXIN 32 & GJB1 & Ser26Trp (major), Arg 142Trp (minor) \\
\hline HNPP & 162500 & $\mathrm{AD}$ & PQ & $17 \mathrm{p} 11.2$ & PMP22 & PMP22 & Deletion \\
\hline SMA & 600354 & $\mathrm{AR}$ & PQ & $5 q 12-q 13$ & SMN & SMN & Deletion \\
\hline
\end{tabular}

AR (autosomal recessive), AD (autosomal dominant), X (X-linked), n.a. (not available), SLSJ (Saguenay-Lac-St-Jean), PQ (Province of Quebec), ? (unknown), FRDA (Friedreich's ataxia), AOA2 (Ataxia with oculomotor apraxia type 2), ARSACS (Autosomal recessive spastic ataxia of Charlevoix-Saguenay), RAB (Recessive ataxia of the Beauce), SPG4 (Spastic paraplegia type 4), ADLD (Autosomal dominant leucodystrophy), AMN (Adrenomyeloneuropathy), SPG27 (spastic paraplegia type 27), HMSN/ACC (hereditary motor and sensory neuropathy with agenesis of the corpus callosum), LHON (Leber hereditary optic neuropathy), HSAN2 (Hereditary sensory and autonomic neuropathy type 2), HMSN (Hereditary motor and sensory neuropathy), HNPP (Hereditary neuropathy with liability to pressure palsy), SMA (Spinal muscular atrophy).

gene is composed of seven exons and encodes a protein named frataxin, which is expressed at high level in the spinal cord, and lower level in the cerebellum and cerebral cortex. ${ }^{14}$ In large studies of Caucasian FRDA patients, there is a strong correlation between the size of the smaller allele (GAA) with the age of onset and the disease progression. ${ }^{15}$ However, when GAA repeat expansion was studied in Acadian FRDA, there seemed to be no correlation between expansion size and severity of clinical features, suggesting that there may be other factors than GAA repeat to explain the clinical variant seen with the major Acadian haplotype. ${ }^{16}$ The pathophysiology of FRDA has been extensively reviewed elsewhere. . $^{5,17}$

\section{Ataxia Oculomotor Apraxia 2 (AOA2, SCAR1; MIM 606002) \\ Clinical features}

Ataxia Oculomotor Apraxia 2 (AOA2) is an autosomal recessive disease with age-dependant penetrance, and age of onset between 10 and 25 years. It is characterized mainly by cerebellar atrophy, axonal sensorimotor neuropathy, oculomotor apraxia, and elevated serum $\alpha$-fetoprotein. ${ }^{18}$ The initial symptom is gait ataxia in the majority of patients, which may be preceded in some patients by strabismus, dystonia, or postural tremor. The disease progresses slowly, with some patients being wheelchair bound after 10 years of onset, while others remain ambulatory well over 20 years of onset. Ataxia is present in all patients in the course of the disease, while other features may also develop such as dystonic postures of the hands, choreic movements, and head or postural tremor. ${ }^{19}$ Some patients may have extensor plantar responses or sphincter disturbances. Clinical signs of a neuropathy (abolished or diminished deep tendon reflexes, sensory or motor deficit) is found in all patients. Cognitive functions may be mildly impaired. Oculomotor apraxia, characterized by a dissociation of eye-head movements, is present in only $56 \%$ of cases worldwide and absent in all FC cases. In addition, saccadic pursuit, gaze-evoked nystagmus, and limited abduction is usually present. ${ }^{19}$ The MRI invariably shows cerebellar atrophy. Compound muscle action potentials C-MAPs and sensory nerve action potentials (SNAPs) show diminished 
amplitudes, consistent with a sensory-motor axonal neuropathy. Serum $\alpha$-fetoprotein is always elevated if measured repeatedly, serum creatine kinase activity may be elevated, and serum albumin level may be low. ${ }^{19}$

\section{Epidemiology, Genetics, and Pathophysiology}

In 1980, Bouchard ${ }^{20}$ described the first FC family with AOA2. The large pedigree included 20 children from the same parents, of which seven were affected. The mother originated from Quebec and the father was Acadian. In the past two years, ten other families of FC ancestry were identified, with a total of 24 affected patients. ${ }^{21}$ All patients presented a fairly homogeneous phenotype, with ataxia beginning from 8 to 16 years, accompanied by a severe sensory-motor polyneuropathy. Oculomotor apraxia was never present. Brain MRI always showed significant pontine and cerebellar atrophy, while serum $\alpha$-fetoprotein was invariably elevated. In $85 \%$ of carrier chromosomes, a shared haplotype was found for markers on chromosome 9q34. ${ }^{21}$ Four mutations in the senataxin gene have been identified in the FC population. ${ }^{21}$ The most common $5927 \mathrm{~T} \rightarrow \mathrm{G}$ founder mutation is shared by $85 \%$ of the carrier chromosomes. The three other mutations are observed in individual families: $193 \mathrm{G} \rightarrow \mathrm{A}, 4087 \mathrm{C} \rightarrow \mathrm{T}$ and 5070insT. There is thus a founder effect for the FC families, and the common mutation may well be of Acadian origin. Though senataxin mutations have been described in many other countries such as Algeria, Vietnam, France, Portugal, Spain, Cabo Verde, Turkey, Japan, Pakistan, Tunisia, the United Kingdom, ${ }^{18}$ and Pakistan, ${ }^{22}$ the FC common mutation has not yet been uncovered in other populations. The estimated carrier rate in the Gaspésie region of Quebec could be as high as $1 / 28$. Little is known of the function of senataxin, but it is thought to have both RNA and DNA helicase activity, and thus may be acting in the DNA repair pathway.

\section{Autosomal Recessive Spastic Ataxia of Charlevoix-Saguenay (ARSACS; MIM 270550)}

\section{Clinical features}

Autosomal Recessive Spastic Ataxia of Charlevoix-Saguenay (ARSACS) patients exhibit early onset signs of spasticity in the lower limbs usually observed at gait initiation (12-18 months). ${ }^{23}$ The clinical picture noticed by the parents from early childhood is always that of a gait ataxia with a tendency to fall. ${ }^{23}$ Spasticity is observable early when there is little sign of cerebellar dysfunction. Speech is slightly slurred in childhood and becomes explosive in adulthood. Early non-progressive signs include bilateral abnormal plantar response, saccadic alteration of smooth ocular pursuit and prominent myelinated fibres radiating from the optic disc and embedding the retinal vessels at fundoscopy. Although there is a slower motor development in ARSACS pre-schoolers, there is no intellectual impairment. The disease progresses more obviously in the teens and twenties, with a progressive increase in muscle tone and deep tendon reflexes. The gait is often jerky, sometimes with scissoring. Discreet to marked distal amyotrophy is usually seen later. Ankle jerks disappear around 25 years of age, having been brisk and polyclonic before in most cases. ${ }^{23}$

Nerve conduction studies demonstrate signs of both early dysmyelination and progressive axonal neuropathy. ${ }^{24}$ C-MAPs show moderately reduced velocities (median nerve $29-44 \mathrm{~m} / \mathrm{s}$, peroneal nerve $17-35 \mathrm{~m} / \mathrm{s}$ ). Usually, by the end of the third decade, distal motor latencies can no longer be recorded in the feet. ${ }^{23}$ SNAPs are all absent. In most cases, needle electromyography shows signs of severe denervation in distal muscles by the twenties. ${ }^{25}$ Atrophy of the superior cerebellar vermis is always present on MRI even in younger patients, and progresses. The inferior vermis remains thicker throughout the disease, and there is progressive cerebellar cortical atrophy.

\section{Epidemiology, Genetics, and Pathophysiology}

With more than 300 affected individuals living in Quebec, ARSACS is the most common of all inherited ataxias in this province. In Quebec, most of the patients' families originate from the regions of Charlevoix and Saguenay-Lac-St-Jean (SLSJ). The estimated carrier frequency is $1 / 22$ in the SLSJ region for the 1941-1985 period. ${ }^{26}$ Although ARSACS is clearly more common in FC than in any population worldwide it has been described in Japan, ${ }^{27}$ Turkey, ${ }^{28,29}$ Tunisia, ${ }^{30,31}$ Italy ${ }^{32,33}$ and Morocco. ${ }^{34}$

The ARSACS gene was mapped to a $0.42 \mathrm{cM}$ interval on chromosome 13q12. ${ }^{35}$ A multi-maker haplotype of the region is conserved by most FC cases, thereby confirming the existence of a founder effect for the common mutation. Two mutations in the SACS gene ${ }^{36}$ have been uncovered in FC cases: the 6594delT frameshift mutation accounts for $94 \%$ of carrier chromosomes; the $5254 \mathrm{C}-\mathrm{T}$ nonsense mutation, predicted to introduce a stop codon, accounts for $3 \%$; in the remaining $3 \%$ of carrier chromosomes, no mutations have been identified as yet. ${ }^{37}$ The SACS gene is encoded by a gigantic exon and also likely includes nine smaller exons upstream. ${ }^{36}$ It codes for the protein sacsin of which the precise function is presently unknown. For the mutations introducing a premature stop codon, it is hypothesized that, since the truncated protein loses its DnaJ and HEPN domains, it may lose some important function related to chaperone-mediated protein folding. For the mutations not causing changes in the predicted secondary structure, a variety of mechanisms may account for their consequences, such as disulfide bridge removal or disruption within the C-terminal HEPN domain. ${ }^{28}$

On autopsy, the superior cerebellar vermis is grossly atrophic, especially in the anterior structures (central lobule and culmen), where Purkinje cells are practically absent, while the molecular and granular layers are thin and poorly populated. ${ }^{38}$ The cerebellar hemispheres are much less involved, with only focal rarefaction of Purkinje cells. Along all segments of the spinal cord there is severe bilateral loss of myelin staining, both in the corticospinal tracts and the adjacent posterior spinocerebellar tracts, while the anterior spinocerebellar tract shows only partial loss of myelin staining. There is no significant alteration of the dorsal columns, dorsal root ganglia, or nerve roots.

\section{Recessive ataxia of Beauce (RAB)}

\section{Clinical features}

This form of ataxia has only recently been characterized. The typical age of onset is in the third decade ranging from 25-46 years and the disease does not appear to affect the lifespan significantly. ${ }^{39}$ There is no evidence of genetic anticipation. The 
mode of inheritance is autosomal recessive with age-dependant penetrance. Overall, the phenotype consists of progressive dysarthria and cerebellar ataxia, with few associated features other than occasional brisk lower extremity tendon reflexes and minor abnormalities in saccades and smooth pursuit. None of the patients show optic atrophy, auditory loss, sensory abnormalities, autonomic disturbances, or extra-pyramidal signs. C-MAPs and SNAPs are normal. Brain MRI invariably shows diffuse cerebellar atrophy.

\section{Epidemiology, Genetics, and Pathophysiology}

A total of ten FC families with this condition have been identified to date in the Chaudière-Appalache and Bas-StLaurent regions of Quebec. A founder effect has been suggested by genealogical reconstruction, all families being traced to common ancestors between the $6^{\text {th }}$ and $9^{\text {th }}$ generations. Linkage to known recessive ataxia loci has been excluded. ${ }^{39}$ An original locus for Recessive ataxia of Beauce (RAB) is soon to be published (G.A.R., personal communication). This distinct neurodegenerative disorder is characterized by diffuse cerebellar atrophy on MRI, with minimal involvement of the pyramidal tracts. No autopsies have been performed. Unlike most other inherited ataxias, its involvement is almost purely of the cerebellum.

\section{Other report}

One of the largest mutation-proven spinocerebellar ataxia type 2 (SCA2) family is FC and many of its members reside in a small coastal village of Gaspésie in Quebec. ${ }^{40}$ Otherwise, SCAs have rarely reported, other than anecdotally, in the FC population.

\section{The Hereditary Spastic Parapareses}

\section{Autosomal Dominant Spastic Paraplegia 4 (SPG 4, FSP2; MIM 182601)}

\section{Clinical features}

The age of onset in Autosomal Dominant Spastic Paraplegia 4 (SPG 4) is very variable, ranging from childhood to elderly, and the disease does not appear to affect lifespan significantly. ${ }^{41}$ There is no evidence of genetic anticipation. The mode of inheritance is autosomal dominant with age-dependant penetrance. Patients may present either with the uncomplicated or complicated phenotype. In the uncomplicated phenotype, symptoms will be limited to a progressive spastic paraparesis with variable degrees of severity, some patients being able to walk independently until late in the disease, and others being wheelchair bound earlier on. ${ }^{41}$ In the complicated form, spastic paraparesis may be associated with neurogenic bladder, fecal incontinence, cognitive abnormalities, seizures, and peripheral neuropathy (loss of vibration, footdrop). ${ }^{41}$ Brain and spinal cord MRI are normal. C-MAPs and SNAPs may be abnormal in the complicated form.

\section{Epidemiology, Genetics, and Pathophysiology}

A total of eight families with this disease have been reported in the FC population, spread across the Province of Quebec. ${ }^{41}$ None of the families reported are known to be related. SPG 4 has also been described in other countries, such as France, ${ }^{42}$ Holland, ${ }^{42}$ England (Welsh origin), ${ }^{43}$ North America (Caucasian), ${ }^{44}$ Tunisia, ${ }^{44}$ and Denmark. ${ }^{45}$ SPG 4 has been mapped to chromosome 2p22-21. All FC families described carry different mutations except two of them, which carry a seemingly more common mutation in Caucasians (G1801A). ${ }^{41}$ No haplotypes have been generated on these Caucasian families, which could confirm that these families share a common historical mutation. Most of the pathologic involvement in SPG 4 , as in other forms of spastic parapareses, is localized to the cortico-spinal tracts. The protein spastin was shown to interact with microtubules through its $\mathrm{N}$-terminal region, and therefore, spastin mutations may impair the regulation of microtubule cytoskeleton in long axons. ${ }^{46}$

\section{Autosomal Dominant Adult-Onset Leucodystrophy (ADLD, PMD-AD-Late-onset type, MS-like disorder; MIM 169500)}

\section{Clinical features}

The typical age of onset is in the third and fourth decade, and the disease does affect the lifespan. The mode of inheritance is autosomal dominant with age-dependant penetrance. Eleven FC patients with ADLD spanning five generations were examined and genealogical studies were performed ${ }^{47}$ The phenotype of the FC families was shown to be similar to that of the other families previously described: the six individuals that were examined showed progressive gait instability, with upper motor neuron involvement (spasticity; hyperreflexia; bilateral extensor plantar responses), and autonomic abnormalities (bowel/bladder dysfunction; orthostatic hypotension). Laboratory investigations were unrevealing (very-long-chain-fatty-acids, arylsulfatase A, galactocerebrosidase, cerebrospinal fluid, nerve conduction studies). The MRI showed mild cerebral atrophy with symmetrical white matter changes most pronounced in frontoparietal regions, with diffuse spinal cord atrophy.

\section{Epidemiology, Genetics, and Pathophysiology}

Three kindreds worldwide have been reported with ADLD, one of FC descent from the Charlevoix region in Quebec, ${ }^{47,48}$ one of Scottish-Irish descent, ${ }^{49}$ and one of American-Irish descent. ${ }^{50}$ Linkage and haplotype analysis within the FC families of markers in the ADLD locus (5q23) revealed a maximum LOD score of 4.08. No autopsies have yet been performed on any of the FC patients. Autosomal Dominant Adult-Onset Leucodystrophy is a disease affecting the autonomic nervous system, the subcortical white matter and, possibly, the corticospinal tract directly.

\section{Other reports}

A woman of FC origin, from the Quebec City area, presenting with spastic paraparesis was found to have a mutation in the ABCD1 gene, thereby confirming the diagnosis of X-linked adrenomyeloneuropathy. ${ }^{51}$ A FC family with a pure HSP phenotype characterized by spastic paraparesis and decreased vibration sense in the lower extremities was identified in the Montreal area. The disease maps to chromosome 10q22-10q24, and overlaps with the SPG9 locus. It is not clear at the present time whether the disease is allelic to SPG9 or represents a new entity, SPG27.52 


\section{The Hereditary Neuropathies}

\section{Hereditary Motor and Sensory Neuropathy with Agenesis of the Corpus Callosum (HMSN/ACC, ACCPN, Andermann Syndrome; MIM 218000)}

\section{Clinical features}

Hereditary Motor and Sensory Neuropathy with Agenesis of the Corpus Callosum (HMSN/ACC) is an autosomal recessive disease of early onset, characterized by a delay in developmental milestones, a severe progressive sensory-motor neuropathy with areflexia, a variable degree of agenesis of the corpus callosum, amyotrophy, hypotonia, cognitive impairment, an atypical psychosis, and occasional dysmorphic features (high arched palate, syndactily). ${ }^{53}$ Other associated features include ptosis, upper gaze palsy, facial asymmetry, tremor, occasional seizures, early Achilles' tendon retraction, and scoliosis. ${ }^{53}$ The disease manifests itself initially by hypotonia and delayed motor milestones. The average age of onset of assisted walking is 3.8 years. The disease progresses relentlessly, and all patients eventually become wheel-chair bound in their teens. The lifespan is shortened, and estimated at about 33 years, although a number of patients have survived into their fifties. ${ }^{53}$ A majority of patients have mild to moderate mental retardation, and close to $40 \%$ of patients develop "psychotic" features in their late teens, characterized by paranoid delusions, visual and auditory hallucinations. ${ }^{54}$ The C-MAPs show a wide degree of variability, being generally reduced in velocity. The SNAPs are invariably absent from birth. ${ }^{53}$ The MRI imaging may show either complete, partial, or no callosal agenesis. ${ }^{53}$

\section{Epidemiology, Genetics, and Pathophysiology}

Hereditary Motor and Sensory Neuropathy with Agenesis of the Corpus Callosum is found mainly in the FC population of Quebec, and specifically in two regions of north-eastern Quebec, the SLSJ region and the Charlevoix County. The carrier rate is estimated at $1 / 23$ inhabitants in the SLSJ region, and genealogical reconstructions have shown that all obligate carriers have common ancestors, thereby supporting a founder effect. $^{55}$ Hereditary Motor and Sensory Neuropathy with Agenesis of the Corpus Callosum has also been reported in other regions worldwide, such as Italy, ${ }^{56,57}$ Austria, ${ }^{58}$ Tanzania, ${ }^{59}$ Turkey, ${ }^{57}$ Holland, and South Africa (personal communication, N Dupré). The basis for a founder effect in the FC population was confirmed by haplotype analysis, which showed that marker D15S1232 is conserved in more than $97 \%$ of affected chromosomes. ${ }^{57}$ Mutations in the SLC12A6 gene, which codes for the potassium chloride cotransporter (KCC3) protein, were found to be responsible for HMSN/ACC. ${ }^{57} \mathrm{KCC} 3$ is expressed in both the central and peripheral nervous system. ${ }^{57}$ The mutant protein is expressed at the cellular membrane, but it is nonfunctional. ${ }^{57}$ Its function is not well understood, but it may be involved in volume regulation, transepithelial transport of salt and water, or in regulation of $\mathrm{K}$ and $\mathrm{Cl}$ concentrations in cells and in the interstitial space. ${ }^{60} \mathrm{~A}$ KCC3-nul mouse model showed abnormal locomotor function, with no anomaly in the central nervous system, but axonal swelling in the peripheral nerves. ${ }^{57}$ Autopsies of patients with HMSN/ACC have been performed, showing sporadic axonal swelling in the white matter, and marked axonal swelling diffusely in the peripheral nervous system. ${ }^{53}$ Hereditary Motor and Sensory Neuropathy with Agenesis of the Corpus Callosum is thus a neurodevelopmental and neurodegenerative disease of the nervous system that may arise secondarily to disturbed ion homeostasis due to loss of function of $\mathrm{KCC} 3$.

\section{Leber Hereditary Optic Neuropathy (LHON; MIM 535000)}

\section{Clinical features}

Leber Hereditary Optic Neuropathy (LHON) patients present with mid-life, acute or subacute, painless, central vision loss leading to central scotoma. Neuro-ophthalmologic examination commonly reveals peripapillary telangiectasia, microangiopathy, disk pseudoedema, and vascular tortuosity. The mean age of onset has been variously reported from 24 to 34 years with a range of 1 to 70 years. The eyes can be affected simultaneously or sequentially, with an average interval between eyes being affected of about two months. The progression of each eye can range from sudden and complete vision loss to progressive decline over two years, with a mean progression time of about 3.7 months. The final visual acuity can range from $20 / 50$ to no light perception, with less severe mutations having less extreme outcomes. The probability of visual recovery also varies in relation to the mutation. ${ }^{61}$ Leber Hereditary Optic Neuropathy patients and their maternal relatives have also been reported to manifest a variety of ancillary symptoms, such as cardiac conduction defects, ${ }^{62}$ multiple sclerosis-like syndromes, ${ }^{63}$ or dystonia and encephalopathy. ${ }^{64}$

\section{Epidemiology, Genetics, and Pathophysiology}

Leber Hereditary Optic Neuropathy has been studied in 42 independently referred patients of FC origin in the Montreal area and its surrounding. ${ }^{65}$ Of these patients, 36 (23 families) carried the T14484C LHON mutation, five (four families) carried the G11778A mutation, and one carried the G3460A mutation. All affected and unaffected members in the matrilineal line of G11778A and T14484C families tested were homoplasmic for the mutations, while heteroplasmy was detected in the G3460A pedigree only. In FC, T14484C is the most frequent mutation, in contrast to all other populations reported, in which G11778A is the most common mutation. This likely represents differences in the population structure. This hypothesis was confirmed by looking at homoplasmic transition mutations, which suggest that FC LHON patients with the T14484 mutation likely share the same maternal lineage and may all have been derived from a single founder woman. ${ }^{66}$ A "Fille du Roy" who married in Quebec city in 1669 was found to have introduced this mutation in the FC population. ${ }^{67}$ The clinical characteristics of T14484C LHON patients are similar to those reported in other populations worldwide concerning male to female ratio, median age at onset, range of age at onset, absence of unilateral visual loss, and median and range of delay of disease onset between eyes. ${ }^{65}$ It is hypothesized that LHON causing mutations result in a defect occurring during the interaction of the NADH generating enzymes and Complex I of the mitochondrial respiratory chain. ${ }^{68}$ It is thought that the degenerative phenotype may be the result of an increase in mitochondrial superoxide, possibly mediated through neuron-specific alterations in complex I structures. ${ }^{69}$ 


\section{Hereditary Sensory and Autonomic Neuropathy Type 2 (HSAN2, HSN2, Neurogenic Acroosteolysis; MIM 201300)}

\section{Clinical features}

Hereditary Sensory and Autonomic Neuropathy Type 2 is an autosomal recessive disease of onset typically in the first two decades. The disease can have a variety of phenotypic manifestations, but the main feature is a loss of sensation in the extremities. The cases described in FC families ${ }^{70-72}$ have the following features: children are usually normal at birth, with normal motor and learning abilities in early childhood; during the first decade, they usually develop signs of abnormal sensation in the extremities (difficulties recognizing objects with their hands, frequent cutaneous bruising and ulcerations); eventually, the patients develop acroosteolysis, evident on clinical examination and on x-Rays of the distal limbs. Autonomic dysfunction such as postural hypotension and decreased sweating is not present. In HSAN 2, C-MAPs are usually within the normal range, although some patients may have diminished amplitudes and conduction velocities, with slightly abnormal eletromyograms. ${ }^{72}$ SNAPs are always abnormal, with either absent potentials, or severely diminished amplitudes. ${ }^{72}$ Axon flare after intradermal histamine is usually absent. $^{73}$

\section{Epidemiology, Genetics, and Pathophysiology}

A total of 12 families of FC origin, from south-western Quebec, have been described with HSAN2. ${ }^{70,72,71}$ These families represent the largest cluster of HSAN 2 described so far. Of 17 cases tested for mutations in the HSAN 2 gene, 7 were homozygous for the c. $943 \mathrm{C} \rightarrow \mathrm{T}$ mutation, one was homozygous for the c.918-919insA mutation, and four were compound heterozygotes of these two mutations. ${ }^{71}$ It was hypothesized that a higher carrier rate of these mutations within the Lanaudière region may have given rise to this occurrence, since consanguinity could not be documented in most cases. ${ }^{71}$ According to biopsy and electrophysiological data, defects in the HSAN 2 gene cause abnormalities both to the sensory and motor nerve fibers, although involvement is more severe in the sensory nerve fibers. Sensory nerve biopsies show severe or complete loss of myelinated fibers. ${ }^{72}$ It is unclear at this stage to what extent the autonomic nervous system is involved. The HSN2 gene is particular in that it consists of a single exon that maps within the intronic region of an other gene, PRPKWNK1. Its function is unknown, but is may conceivably be a secreted protein and possibly be a novel neurotrophic factor. ${ }^{73}$

\section{Hereditary Motor and Sensory Neuropathies (HMSN)}

\section{Clinical features}

Hereditary Motor and Sensory Neuropathies (HMSN) represent a group of clinically and genetically heterogeneous disorders affecting the peripheral nervous system. ${ }^{74}$ Hereditary Motor and Sensory Neuropathies are clinically characterized by progressive weakness and atrophy of distal muscles of both lower and upper extremities. The severity of the disease varies between patients, even within the same family, from almost no symptoms to severe foot-drop. Neurophysiological and histopathological criteria are used to differentiate HMSNs into two main forms. ${ }^{74}$ The HMSN Type 1A (CMT 1A; MIM 118220) and HMSN Type X1 (CMT X1; MIM 302800) are known as demyelinating forms of HMSN, since electrophysiological studies show decreased nerve conduction velocities on C-MAPs and SNAPs. Hereditary Motor and Sensory Neuropathies Type 2 are known as axonal forms of HMSN, since electrophysiological studies show normal nerve conduction velocities with decreased amplitudes on C-MAPs and SNAPs. Hereditary neuropathy with liability to pressure palsy (HNPP; MIM 162500) presents as a painless mononeuropathy that develops after minor trauma or compression of a peripheral nerve. ${ }^{74}$ Weakness and sensory symptoms disappear within days or weeks. Electrophysiological studies show localized reduction of the nerve conduction velocity in the region of nerve injury.

\section{Epidemiology, Genetics, and Pathophysiology}

Hereditary Motor and Sensory Neuropathies 1A, HMSN X1, HMSN 2, and HNPP have all been described in the FC population. ${ }^{75,76}$ Hereditary Motor and Sensory Neuropathies 1A was found to be as frequent $(72 \%)$ in the FC population as in other populations as a cause of demyelinating HMSN. ${ }^{53}$ Frequencies of other causes of demyelinating HMSNs, such as HMSN 1B were not evaluated. Overall, the phenotype of HMSN 1A was similar to that reported in other populations regarding age of onset, clinical features, and electrophysiological studies. ${ }^{53}$ Additionally, relative frequencies of demyelinating and axonal HMSNs were reported to be similar to that in other populations ( $81 \%$ for HMSN 1, and $19 \%$ for HMSN 2). ${ }^{53}$ As for HMSN X1, a founder mutation (Ser26Trp) was identified in four families seemingly unrelated, presenting with the classical HMSN X1 phenotype. ${ }^{76}$ The founder effect was demonstrated by haplotype analysis, and these families all came from the Portneuf area of the Province of Quebec. As for HNPP, three FC families with the typical phenotype have been identified in the Quebec City area, showing the PMP22 deletion on genetic testing (ND, personal communication). Finally, an Acadian pedigree from Louisiana, with the demyelinating form of HMSN, was mapped to the HMSN 1A locus. ${ }^{77}$ To our knowledge, no other HMSN 1a families have been reported in Acadians of Canada, but it could very well be that some of the pedigrees reported in Quebec were in fact of Acadian ancestry. The genetics and pathophysiology of HMSNs have been extensively reviewed elsewhere. ${ }^{78}$

\section{Other reports}

A study of 58 spinal muscular atrophy (SMA) cases of FC origin showed similar proportions of the various subtypes of the disease (Types 1, $2 \& 3$ ), with a founder haplotype found in $36 \%$ of SMA type 1 and $23 \%$ of SMA type 2 chromosomes. ${ }^{79}$

We have summarized our current knowledge of the various hereditary ataxias, spastic parapareses and neuropathies in the FC population. The following neurogenetic disorders were first identified in patients of FC origin: AOA2, ARSACS, HSAN2, $\mathrm{RAB}$, and HMSN/ACC. It has been demonstrated for many inherited diseases that historical events have shaped the various regional gene pools of Quebec and New Brunswick. ${ }^{80}$ In doing so it has given rise to the increased prevalence of some rare diseases due to founder effects. The study of the more common and homogenous of these diseases has been largely completed. 
The regional populations of Canada we are convinced will still allow the identification of new rarer forms of hereditary ataxias, spastic parapareses and neuropathies, and contribute to the uncovering of their mutated genes.

\section{REFERENCES}

1. Bouchard G, De Braekeleer M. Histoire d'un génôme. Québec: Presses de l'Université du Québec, 1991:607.

2. Theriault R. L'Acadie 1604-2004. Cap-aux-diamants: la revue d'histoire du Québec. 2004;77:10-4.

3. Barbeau A. Distribution of Ataxia in Quebec. In: Sobue I, editor. Spinocerebellar degenerations. Tokyo: Japanese Medical Research Foundation; 1978. p.121-42.

4. Harding AE. Friedreich's ataxia: a clinical and genetic study of 90 families with an analysis of early diagnostic criteria and intrafamilial clustering of clinical features. Brain. 1981;104:589620.

5. Alper G, Narayanan V. Friedreich's ataxia. Pediatr Neurol. 2003;28:335-41.

6. Bouchard JP, Barbeau A, Bouchard R, Paquet M, Bouchard RW, et al. A cluster of Friedreich's ataxia in Rimouski, Quebec. Can J Neurol Sci. 1979;6:205-8.

7. Barbeau A, Sadibelouiz M, Roy M, Lemieux B, Bouchard JP, Geoffroy G, et al. Origin of Friedreich's disease in Quebec. Can J Neurol Sci. 1984;11:506-9.

8. Chamberlain S, Shaw J, Wallis J, Rowland A, Chow L, Farrall M, et al. Genetic homogeneity at the Friedreich ataxia locus on chromosome 9. Am J Hum Genet. 1989;44:518-21.

9. Barbeau A, Roy M, Sadibelouiz M, Wilensky MA. Recessive ataxia in Acadians and "Cajuns". Can J Neurol Sci. 1984;11:526-33.

10. Keats BJ, Ward LJ, Shaw J, Wickremasinghe A, Chamberlain S. "Acadian" and "classical" forms of Friedreich ataxia are most probably caused by mutations at the same locus. Am J Med Genet. 1989;33:266-8.

11. Sirugo G, Duclos F, Fujita R, Keats JB, Pandolfo M, Mandel JL, et al. Mapping the Friedreich ataxia locus (FRDA) by linkage disequilibrium analysis with highly polymorphic microsatellites. Biomed Pharmacother. 1994; 48:219-24.

12. Richter A, Poirier J, Mercier J, Julien D, Morgan K, Roy M, et al. Friedriech ataxia in Acadian families from Easter Canada: Clinical diversity with conservered haplotypes. Am J Med Genet. 1996;64:594-601

13. Sirugo G, Keats B, Fujita R, Duclos F, Purohit K, Koenig M, et al. Friedreich ataxia in Louisiana Acadians: demonstration of a founder effect by analysis of microsatellite-generated extended haplotypes. Am J Hum Genet. 1992;50:559-66.

14. Campuzano V, Montermini L, Molto M, Pianese L, Cossee M, Cavalcanti F, et al. Friedriech ataxia: autosomal recessive disease caused by an intronic GAA triplet repeat expansion. Science. 1996;271:1423-7.

15. Durr A, Cossee M, Agid Y, Campuzano V, Mignard C, Penet C, et al. Clinical and genetic abnormalities in patients with Friedreich's ataxia. N Engl J Med. 1996; 335:1169-75.

16. Montermini L, Richter A, Morgan K, Justice CM, Julien D, Castellotti B, et al. Phenotypic variability in Friedreich ataxia: role of the associated GAA triplet repeat expansion. Ann Neurol. 1997; 41:675-82.

17. Voncken M, Ioannou P, Delatycki MB. Friedreich ataxia-update on pathogenesis and possible therapies. Neurogenetics. 2004;5:1-8.

18. Moreira MC, Klur S, Watanabe M, Nemeth AH, LeBer I, Moniz JC, et al. Senataxin, the ortholog of a yeast RNA helicase, is mutant in ataxia-ocular apraxia 2. Nat Genet. 2004;36:225-7.

19. Le Ber I, Bouslam N, Rivaud-Pechoux S, Guimaraes J, Benomar A, Chamayou $\mathrm{C}$, et al. Frequency and phenotypic spectrum of ataxia with oculomotor apraxia 2: a clinical and genetic study in 18 patients. Brain. 2004;127:759-67.

20. Bouchard J, Bedard P, Bouchard R. Study of a family with progressive ataxia, tremor and severe distal amyotrophy. Can J Neurol Sci. 1980;7:345-9.

21. Duquette A, Roddier K, McNabb-Baltar J, Gosselin I, St-Denis A, Dicaire MJ, et al. Mutations in senataxin responsible for Quebec cluster of ataxia with neuropathy. Ann Neurol. 2005;57:408-14.
22. Nemeth AH, Bochukova E, Dunne E, Huson SM, Elston J, Hannan MA, et al. Autosomal recessive cerebellar ataxia with oculomotor apraxia (ataxia-telangiectasia-like syndrome) is linked to chromosome 9q34. Am J Hum Genet. 2000;67:1320-6.

23. Bouchard JP, Richter A, Mathieu J, Brunet D, Hudson TJ, Morgan $\mathrm{K}$, et al. Autosomal recessive spastic ataxia of CharlevoixSaguenay. Neuromuscul Disord. 1998;8:474-9.

24. Peyronnard JM, Charron L, Barbeau A. The neuropathy of Charlevoix-Saguenay ataxia: an electrophysiological and pathological study. Can J Neurol Sci. 1979;6:199-203.

25. Bouchard JP, Barbeau A, Bouchard R, Bouchard RW. Autosomal recessive spastic ataxia of Charlevoix-Saguenay. Can J Neurol Sci. 1978;5:61-9.

26. De Braekeleer M, Giasson F, Mathieu J, Roy M, Bouchard JP, Morgan K, et al. Genetic epidemiology of autosomal recessive spastic ataxia of Charlevoix-Saguenay in northeastern Quebec. Genet Epidemiol. 1993;10:17-25.

27. Hara K, Onodera O, Endo M, Kondo H, Shiota H, Miki K, et al. Sacsin-related autosomal recessive ataxia without prominent retinal myelinated fibers in Japan. Mov Disord. 2005;20:380-2.

28. Richter AM, Ozgul RK, Poisson VC, Topaloglu H. Private SACS mutations in autosomal recessive spastic ataxia of CharlevoixSaguenay (ARSACS) families from Turkey. Neurogenetics. 2004;5:165-170.

29. Gucuyener K, Ozgul K, Paternotte C, Erdem H, Prud'homme JF, Ozguc $\mathrm{M}$, et al. Autosomal recessive spastic ataxia of Charlevoix-Saguenay in two unrelated Turkish families. Neuropediatrics. 2001;32:142-6.

30. El Euch-Fayache G, Lalani I, Amouri R, Turki I, Ouahchi K, Hung WY, et al. Phenotypic features and genetic findings in sacsinrelated autosomal recessive ataxia in Tunisia. Arch Neurol. 2003;60:982-8.

31. Mrissa N, Belal S, Hamida CB, Amouri R, Turki I, Mrissa R, et al. Linkage to chromosome 13q11-12 of an autosomal recessive cerebellar ataxia in a Tunisian family. Neurology. 2000;54:140814

32. Grieco GS, Malandrini A, Comanducci G, Leuzzi V, Valoppi M, Tessa A, et al. Novel SACS mutations in autosomal recessive spastic ataxia of Charlevoix-Saguenay type. Neurology. 2004;62:103-6.

33. Criscuolo C, Banfi S, Orio M, Gasparini P, Monticelli A, Scarano V, et al. A novel mutation in SACS gene in a family from southern Italy. Neurology. 2004;62:100-2.

34. Lamy C, Melançon S, Taussig D, Richter A, Bouchard JP, Mas JL, et al. Ataxie spastique récessive de type Charlevoix-Saguenay dans une famille marocaine. Revue Neurologique. 1998;154:463.

35. Richter A, Rioux JD, Bouchard JP, Mercier J, Mathieu J, Ge B, et al. Location score and haplotype analyses of the locus for autosomal recessive spastic ataxia of Charlevoix-Saguenay, in chromosome region 13q11. Am J Hum Genet. 1999;64:768-75.

36. Engert JC, Berube P, Mercier J, Dore C, Lepage P, Ge B, et al. ARSACS, a spastic ataxia common in northeastern Quebec, is caused by mutations in a new gene encoding an 11.5-kb ORF. Nat Genet. 2000;24:120-5.

37. Mercier J, Prevost C, Engert JC, Bouchard JP, Mathieu J, Richter A. Rapid detection of the sacsin mutations causing autosomal recessive spastic ataxia of Charlevoix-Saguenay. Genet Test. 2001;5:255-9.

38. Bouchard JP. Recessive spastic ataxia of Charlevoix-Saguenay. In: de Jonghe JMBV, editor. Hereditary neuropathies and spinocerebellar atrophies. Vol. 16 (60). Amsterdam: Elsevier Science Publisher; 1991. p.451-9.

39. Dupré N, Bouchard JP, Verreault S, Rivest D, Puymirat J, Rouleau G. Recessive ataxia of the Beauce, a new form of hereditary ataxia of pure cerebellar type. Neurology. 2002;58:A35

40. Lopes-Cendes I, Andermann E, Attig E, Cendes F, Bosch S, Wagner $\mathrm{M}$, et al. Confirmation of the SCA-2 locus as an alternative locus for dominantly inherited spinocerebellar ataxias and refinement of the candidate region. Am J Hum Genet. 1994;54:774-81.

41. Meijer IA, Hand CK, Cossette P, Figlewicz DA, Rouleau GA. Spectrum of SPG4 mutations in a large collection of North American families with hereditary spastic paraplegia. Arch Neurol. 2002;59:281-6. 
42. Hazan J, Lamy C, Melki J, Munnich A, de Recondo J, Weissenback J. Autosomal dominant familial spastic paraplegia is genetically heterogeneous and one locus maps to chromosome 14q. Nat Genet. 1993;5:163-7.

43. Reid E, Grayson C, Rubinsztein DC, eRogers MT, Rubinsztein JS. Subclinical cognitive impairment in autosomal dominant "pure" hereditary spastic paraplegia. J Med Genet. 1999;36:797-8.

44. Hentati A, Pericak-Vance MA, Lennon F, Wasserman B, Hentati F, Juneja $\mathrm{T}$, et al. Linkage of a locus for autosomal dominant familial spastic paraplegia to chromosome $2 \mathrm{p}$ markers. Hum Mol Genet. 1994;3:1867-71.

45. Nielsen JE, Koefoed P, Abell K, Hasholt L, Eiberg H, Fenger K, et al. CAG repeat expansion in autosomal dominant pure spastic paraplegia linked to chromosome 2p21-p24. Hum Mol Genet. 1997;6:1811-6.

46. Errico A, Ballabio A, Rugarli EI. Spastin, the protein mutated in autosomal dominant hereditary spastic paraplegia, is involved in microtubule dynamics. Hum Mol Genet. 2002;11:153-63.

47. Simoes Lopes A, Verreault S, Bouchard JP, Rouleau GA. Further evidence of linkage between adult-onset autosomal dominant leukodystrophy and chromosome 5q23. Am J Hum Genet. 2002;73:471.

48. Verreault S, Langlois M, Thibault M, Bouchard JP, Simoes Lopes A, Rouleau GA. A kindred of hereditary adult-onset autosomal dominant leukodystrophy in Charlevoix, Quebec. Can J Neurol Sci. 2002;29:S57.

49. Brown RT, Polinsky RJ, Schwankhaus J, Eldridge R, McFarland H, Schesinger $\mathrm{S}$, et al. Adrenergic dysfunction in hereditary adultonset leukodystrophy. Neurology. 1987;37:1421-4.

50. Eldridge R, Anayiotos CP, Schlesinger S, Cowan D, Bever C, Patronas $\mathrm{N}$, et al. Hereditary adult-onset leukodystrophy simulating chronic progressive multiple sclerosis. N Engl J Med. 1984;311:948-53.

51. Dionne A, Brunet D, MacCampbell A, Dupre N. Adrenomyeloneuropathy: report of a new mutation in the $\mathrm{ABCD} 1$ gene in a French-Canadian. Can J Neurol Sci. 2005;32:261-3.

52. Meijer IA, Cossette P, Roussel J, Benard M, Toupin S, Rouleau GA, et al. A novel locus for pure recessive hereditary spastic paraplegia maps to 10q22.1-10q24.1. Ann Neurol. 2004;56:57982.

53. Dupre N, Howard HC, Mathieu J, Karpati G, Vanasse M, Bouchard JP, et al. Hereditary motor and sensory neuropathy with agenesis of the corpus callosum. Ann Neurol. 2003;54:9-18.

54. Filteau M, Pourche E, Bouchard R, Baruch P, Mathieu J, Bedard F, et al. Corpus callosum agenesis and psychosis in Andermann syndrome. Arch Neurol. 1991;48:1275-80.

55. De Braekeleer M, Dallaire A, Mathieu J. Genetic epidemiology of sensorimotor polyneuropathy with or without agenesis of the corpus callosum in northeastern Quebec. Hum Genet. 1993;91:223-7.

56. Battistella P, Drigo P, Laverda A, Casara G, De Martin P, Condini A, et al. The Andermann syndrome. Progressive neuropathy, mental retardation with agenesis of the corpus callosum. Ital J Pediatrics. 1987;13:200-2.

57. Howard H, Mount D, Rochefort D, Dupre N, Prevost C, Welch R, et al. Mutations in the K-Cl cotransporter KCC3 cause a severe peripheral neuropathy associated with agenesis of the corpus callosum. Nat Genet. 2002;32:384-92.

58. Hauser E, Bittner P, Liegl C, Bernert G, Zeitlofer J. Occurrence of Andermann Syndrome out of French Canada - agenesis of the corpus callosum with neuronopathy. Neuropediatrics. 1993; 24:107-10.

59. Deleu D, Bamanikar S, Muirhead D, Louon A. Familial progressive sensorimotor neuropathy with agenesis of the corpus callosum (Andermann Syndrome): A clinical, neuroradiological and histopathological study. Eur Neurol. 1997;37:104-9.

60. Race J, Makhlouf F, Logue P Wilson F, Dunham P, Holtzman E. Molecular cloning and functional characterization of KCC3, a new K-Cl cotransporter. Am J Physiol. 1999;277:C1210-C1219.

61. Newman NJ. Leber's hereditary optic neuropathy. New genetic considerations. Arch Neurol. 1993;50:540-8.

62. Nikoskelainen E, Wanne O, Dahl M. Pre-excitation syndrome and Leber's hereditary optic neuroretinopathy. Lancet. 1985;1:696.
63. Newman NJ, Lott MT, Wallace DC. The clinical characteristics of pedigrees of Leber's hereditary optic neuropathy with the 11778 mutation. Am J Ophthalmol. 1991;111:750-62.

64. Gropman A, Chen TJ, Perng CL, Krasnewich D, Cherfnoff E, Tifft $\mathrm{C}$, et al. Variable clinical manifestation of homoplasmic G14459A mitochondrial DNA mutation. Am J Med Genet. 2004;124A:377-82.

65. Macmillan C, Kirkham T, Fu K, Allison V, Andermann E, Chitayat $\mathrm{D}$, et al. Pedigree analysis of French Canadian families with T14484C Leber's hereditary optic neuropathy. Neurology. 1998;50:417-22.

66. Macmillan C, Johns TA, Fu K, Shoubridge EA. Predominance of the T14484C mutation in French-Canadian families with Leber hereditary optic neuropathy is due to a founder effect. Am J Hum Genet. 2000;66:332-5.

67. Laberge AM, Jomphe M, Houde L, Vezina H, Tremblay M, Desjardins B, et al. A "Fille du Roy" introduced the T14484C Leber Hereditary Optic Neuropathy Mutation in French Canadians. Am J Hum Genet. 2005;77.

68. Larsson NG, Andersen O, Holme E, Oldfors A, Wahlstrom J. Leber's hereditary optic neuropathy and complex I deficiency in muscle. Ann Neurol. 1991;30:701-8.

69. Wong A, Cavelier L, Collins-Schramm HE, Seldin MF, McGrogan M, Savontaus ML, et al. Differentiation-specific effects of LHON mutations introduced into neuronal NT2 cells. Hum Mol Genet. 2002;11:431-8

70. Hould F, Verret S. Hereditary radicular neuropathy with sensory loss: study of a French-Canadian family. Laval Med. 1967;38:454-9.

71. Roddier K, Thomas T, Marleau G, Gagnon AM, Dicaire MJ, StDenis A, et al. Two mutations in the HSN2 gene explain the high prevalence of HSAN2 in French Canadians. Neurology. 2005;64:1762-7.

72. Ohta M, Ellefson RD, Lambert EH, Dyck PJ. Hereditary sensory neuropathy, type II. Clinical, electrophysiologic, histologic, and biochemical studies of a Quebec kinship. Arch Neurol. 1973;29:23-37.

73. Lafreniere RG, MacDonald ML, Dube MP, MacFarlane J, O'Driscoll M, Brais B, et al. Identification of a novel gene (HSN2) causing hereditary sensory and autonomic neuropathy type II through the study of Canadian genetic isolates. Am J Hum Genet. 2004:74:1064-73.

74. Timmerman V, Nelis E, De Jonghe P, Martin JJ, Van Broeckhoven C. Hereditary neuropathies. In: Emery AEH, editor. Neuromuscular disorders:clinical and molecular genetics. West Sussex: John Wiley \& Sons Ltd; 1998. p.487-511.

75. Dupre N, Bouchard JP, Cossette L, Brunet D, Vanasse M, Lemieux $\mathrm{B}$, et al. Clinical and electrophysiological study in FrenchCanadian population with Charcot-Marie-tooth disease type 1A associated with $17 \mathrm{p} 11.2$ duplication. Can J Neurol Sci. 1999;26:196-200.

76. Dupre N, Cossette L, Hand CK, Bouchard JP, Rouleau GA, Puymirat J. A founder mutation in French-Canadian families with X-linked hereditary neuropathy. Can J Neurol Sci. 2001;28:51-5.

77. Patel PI, Franco B, Garcia C, Slaugenhaupt SA, Nakamura Y, Ledbetter DH, et al. Genetic mapping of autosomal dominant Charcot-Marie-Tooth disease in a large French-Acadian kindred: identification of new linked markers on chromosome 17. Am J Hum Genet. 1990;46:801-9.

78. Berger P, Young P, Suter U. Molecular cell biology of CharcotMarie-Tooth disease. Neurogenetics. 2002;4:1-15.

79. Simard LR, Rochette C, Semionov A, Morgan K, Vanasse M. SMN(T) and NAIP mutations in Canadian families with spinal muscular atrophy (SMA): genotype/phenotype correlations with disease severity. Am J Med Genet. 1997;72:51-8.

80. Scriver CR. Human genetics: lessons from Quebec populations. Annu Rev Genomics Hum Genet. 2001;2:69-101. 